\title{
Enhancement of power system performance with wind farm disturbances
}

\author{
Mahmoud M. El-Sharkawy ${ }^{1}$, Mahmoud A. Attia ${ }^{2}$, Almoataz Y. Abdelaziz ${ }^{3}$ \\ ${ }^{1,2}$ Department of Electrical Power and Machines, Ain Shams University, Egypt \\ ${ }^{3}$ Faculty of Engineering \& Technology, Future University in Egypt, Cairo, Egypt
}

\section{Article Info \\ Article history: \\ Received Nov 2, 2018 \\ Revised Jan 29, 2019 \\ Accepted Feb 12, 2019}

\section{Keywords:}

Doubly fed induction generator Pitch angle controller Wind turbine efficiency

\begin{abstract}
This paper discussed how wind farm disturbance, especially wind speed variability, can affect the performance of the power system. Also, it discussed how blades angels of wind turbine can be controlled to increase the energy efficacy of the power system. It showed that the optimized pitch angel controller using harmony search algorithm could enhance blades angels' adjustments performance. First part, the paper explained the advantages of doubly fed induction generator in wind turbine system. Paper also enumerated the most probable ways to tame the wind speed variability challenge focusing on the pitch angle controller technique. After that, paper compared the system parameter`s result before optimization with values after optimized pitch angle controller gain (Kp). This comparison would be held in three cases, case of variable wind speed with normal operation condition, constant wind speed with line to ground fault condition and variable wind speed with line to ground fault condition. Finally, It demonstrated the MATLAB/SIMULINK model used illustrating results appeared and conclusion.
\end{abstract}

Copyright ( 12019 Institute of Advanced Engineering and Science. All rights reserved.

\section{Corresponding Author:}

Mahmoud Maged Abdel Azeem El-Sharkawy, Department of Electrical Power and Machines, Ain Shams Univesity, 1 Elsarayat St., Abbaseya, 11517 Cairo, Egypt. Email: mahmoud.elsharkawy1991@gmail.com

\section{INTRODUCTION}

Increased growth of energy demand coupled with fossil fuel resources depletion and environment concerns has urge society to search for an alternate renewable energy sources. Out of available renewables, Wind energy has proved itself as an attractive solution for wide geography for many reasons [1]. It's considered as agreen energy source, it needs low running cost and it allows more than $90 \%$ of used land to be used for cultivation.

Fixed speed wind turbine (FSWT) and variable speed wind turbine (VSWT) are the most popular types of wind turbines as they are able to extract optimum power which improving overall efficiency.

One of the best variable speed wind turbine is the doubly fed induction generator (DFIG). DFIG is currently one of the most popular wind energy extraction system Figure 1 [2-4]. DFIG solution has proved itself as one of the most practical wind energy extraction solution. With reduced Converters rating approximately (20-30) \% of the total generator power. This means that the losses in the power electronic equipment can be reduced in comparison to FSWT or VSWT. Speed variation of (30\%) around synchronous speed can be obtained which means more energy captured from the wind as shown in Figure 2. Also it can transmit power for the grid through both stator and rotor. Moreover, it offers reduced mechanical stress on the wind turbine [5]. The DFIG allows decoupled control of active $\&$ reactive power $[3,6,7]$. 


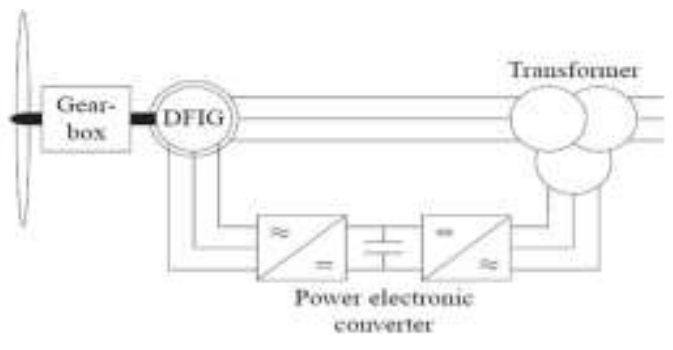

Figure 1. Double fed induction generator (DFIG)

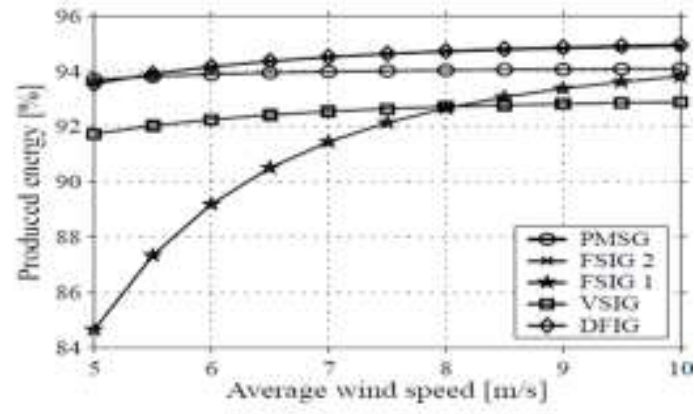

Figure 2. Comparison between different turbines for Produced Energy at different wind speeds

\section{WIND SPEED VARIABILITY}

Stochastic nature of wind speed comes from its dependency on weather and climatic conditions. This comprises a crucial Challenge for Power Extraction operation [2, 8]. Wind Speed variability is considered the main challenge for many power system issues including Power quality, Power factor and voltage regulation.

Figure 3 shows a particular site in Ireland, A (36-hour) ahead wind speed forecast in hourly steps for three distinct days is done as shown in Figure 3, making a comparison between the actual and forecasted values. In general, wind speed predictions are seen to be reasonable, with little fall-off in performance for longer time horizons. Figure $3 \mathrm{~b}$ illustrates fairly unusual day, when looking (10hours) ahead the actual wind resource is significantly greater than predicted [8].
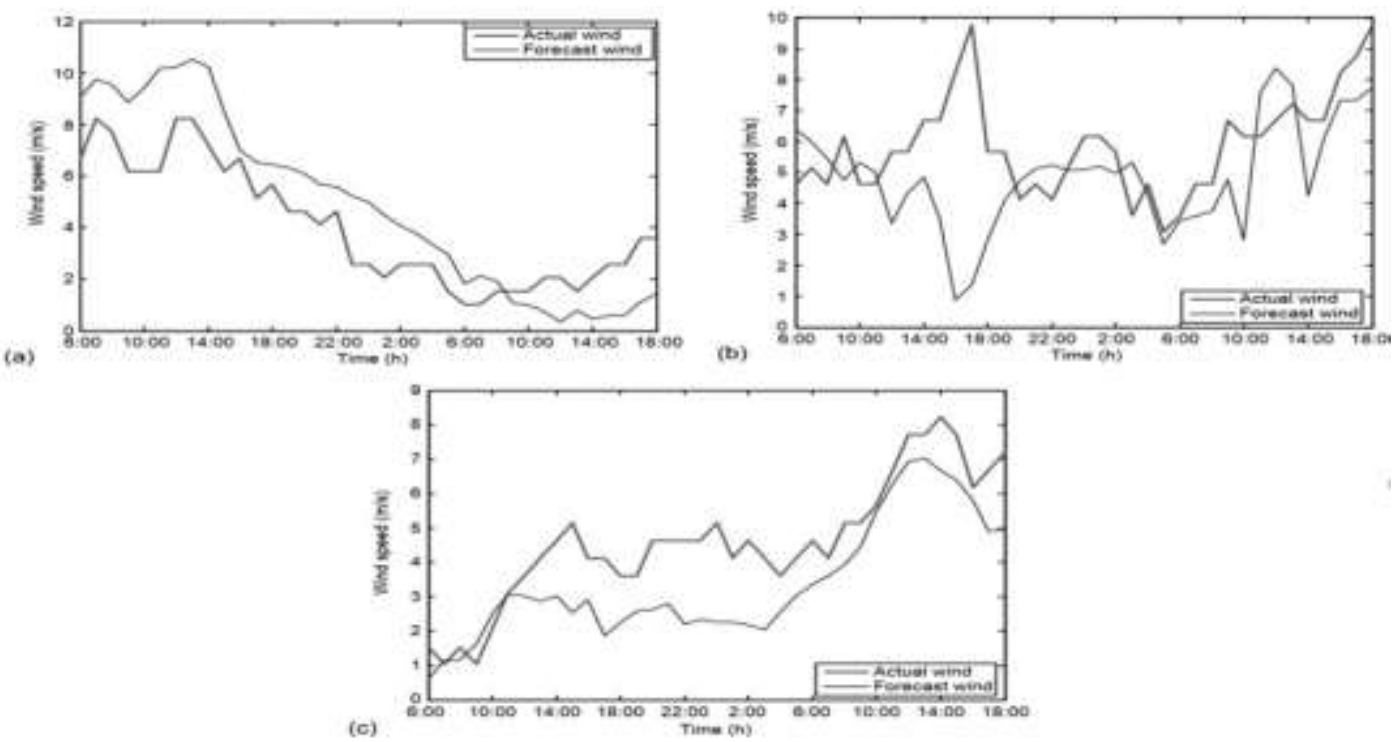

Figure 3. 36-hour ahead wind speed prediction (a, b and c) 
Wind speed variability issue and its effect on power system quality have motivated reaserchers to obtain asolution to this problem. There are many techniques have been studied to overcome this problem. Amoung these solutions, rotor and stator side converters control are produced [9-10]. Also, pitch angle control technique has proved itself as one of the most effective wind speed control techniques enhancing wind turbine performance. It has been studied using many optimization techniques such as Fuzzy logic control [11]. Herein, it will be studied based on harmony search algorithm.

\subsection{Pitch angle controller:-}

Pitch angle controller enables operator to adjust all blades at the same time or each one separately. By pitching the blades towards wind maximizing energy captured or pitching blades away discarding the excess power, the blades regulate the power captured by rotor keeping power and speed at their rated values. Also, to prohibit any mechanical failure due to blades over speed [4]. Pitch angle control is limited to about $(10 \%$ s) during normal operation and $(20 \%)$ for emergencies [3]. The extracted wind energy is affected by the rotor power coefficient $(\mathrm{Cp})$ as in [1], [2]. Determination of that coefficient is dependent on the aerodynamic parameters for each turbine. Performance curves which provide information about efficiency of the turbine for different wind speeds and various blades angles can also illustrate the condition at which maximum power coefficient $(\mathrm{Cp})$ could be obtained. This is shown in Figure 4 [12]. To calculate it the following equations are used [13].

$$
\begin{aligned}
& P_{t}=\frac{1}{2} \rho v^{3} C_{p} \\
& C_{p}=\frac{P_{\text {wind turbine }}}{P_{\text {air }}} \\
& C_{P}=C_{1}\left(\frac{C_{2}}{\lambda_{i}}-C_{3} \beta-C_{4}\right) e^{\frac{-C_{5}}{\lambda_{i}}} \\
& \frac{1}{\lambda_{i}}=\left(\frac{1}{\lambda+C_{6} \beta}-\frac{C_{7}}{\beta^{3}+1}\right)
\end{aligned}
$$

Where Pt is the mechanical output power of the turbine (w). $\rho$ is the air density (approximately $\left.1.225 \mathrm{~kg} / \mathrm{m}^{3}\right)$. A is the swept area of rotor $\left(\mathrm{m}^{2}\right) . v$ is the wind speed $(\mathrm{m} / \mathrm{s}) . \mathrm{C} 1, \mathrm{C} 2, \ldots, \mathrm{C} 7$ are the turbine Aerodynamic. $\beta$ is the pitch angle. $\lambda$ is the turbine tip speed ratio. Form (3-4) Performance curve can be drawn for different pitch angle values.as shown in Figure 4. These curves illustrate the maximum energy extraction points and show that the power coefficient is inversely proportional to the pitch angle value.

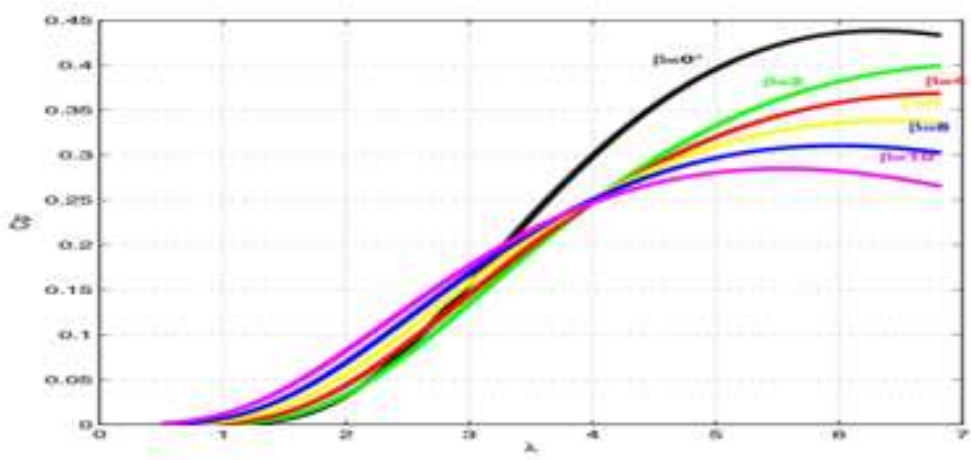

Figure 4. Power coefficient vs. tip speed ratio for various values of pitch angle

Figure 5 shows a model of pitch angle controller. A reference rate of change of pitch is generated using PI controller. This reference is limited. A first order system gives the dynamic behavior of speed control of pitch variation. By integrating the variation of the angle, pitch angle is obtained [3].

In this paper, pitch angle control based on harmony search optimization technique will be considered. System in Figure 6 will be studied at three cases. The first case will be the system at normal condition, in case of variable wind speed. Second one will be the system at fault condition, line to ground fault, in case of constant wind speed. Finally, the system at fault condition, line to ground fault, in case of

Enhancement of power system performance with wind farm disturbances (Mahmoud M. El-Sharkawy) 
variable wind speed. In each case optimization of blade angle control will be carried out by the harmony search algorithm (HAS) techinique.

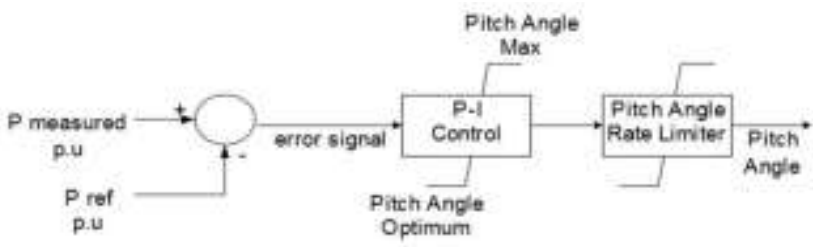

Figure 5. Pitch angle controller configuration

\section{DFIG WIND FARM MODEL IMPLEMENTATION AND SIMULATION RESULTS [14]}

Figure 6 shows a wind farm represented by one $(1.5 \mathrm{MW})$ wind turbine connected to a $120 \mathrm{kV}, 60$ HZ frequency power system through (2500MVA) Transmission line. A step down transformer (120/25) KV of 47 MVA power is connected to a 25 Kilo- meters transmission line, where the studied fault is subjected in the middle of it. Then to a step down transformer (25/.575) KV of 1.5 MVA power through appoint of common coupling with the wind turbine and an arbitrary load of 20 watt. A doubly-fed induction generator, DFIG, which is consisting of a wound rotor induction machine. Its stator is directly connected to the power grid while rotor is connected to power grid through AC/DC/AC IGBT-based PWM converters. A DC Bus link of $1200 \mathrm{~V}$ and Capacitor of size (10000e-6) farad. With starting Pitch angle gain value of $(\mathrm{Kp}=500)$ and maximum pitch angle of 45 degree [14].

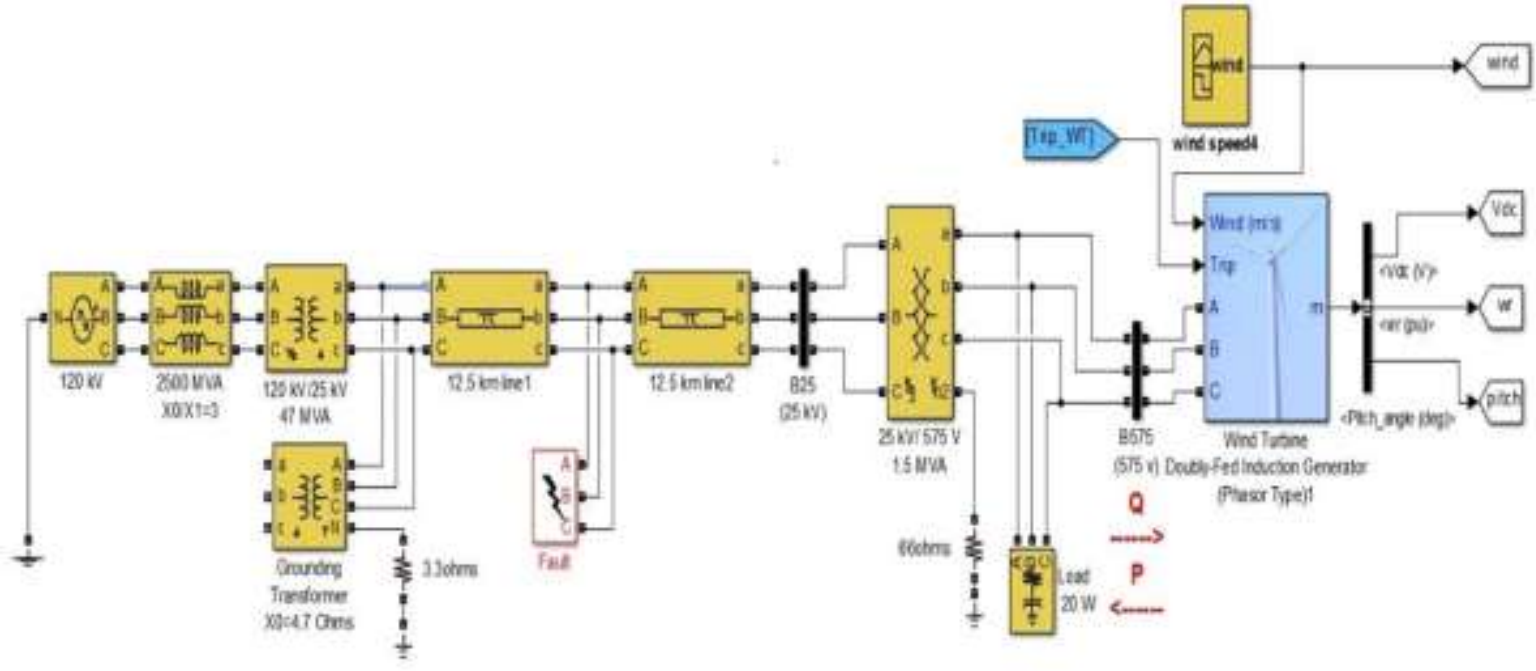

Figure 6. DFIG wind farm model represented by MATLAB/SIMULINK

\subsection{Harmony search algorithm $[15,16]$}

It's a music-based meta-heuristic optimization algorithm. It was inspired by the improvisation of Jazz musicians as shown in Figure 7. It`s firstly proposed by Zong Woo Geem in 2001. Figure 7 shows the analogy between the music improvisation and the engineering optimization process. 


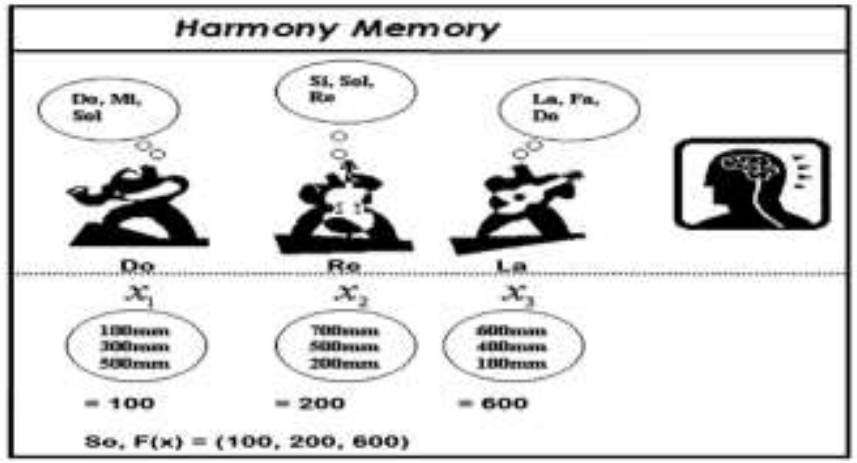

Figure 7. Analogy between the Music improvisation and engineering optimization process

In HSA, each decision variable generates a value to find the best harmony, global optimum, all together as shown in Figure 8. HS algorithm does not require initial values for the decision variables. Also, HS uses stochastic random search instead of gradient search. This random search is based on the harmony memory considering rate and pitch adjusting rate so that derivative information is not necessary [15-16].

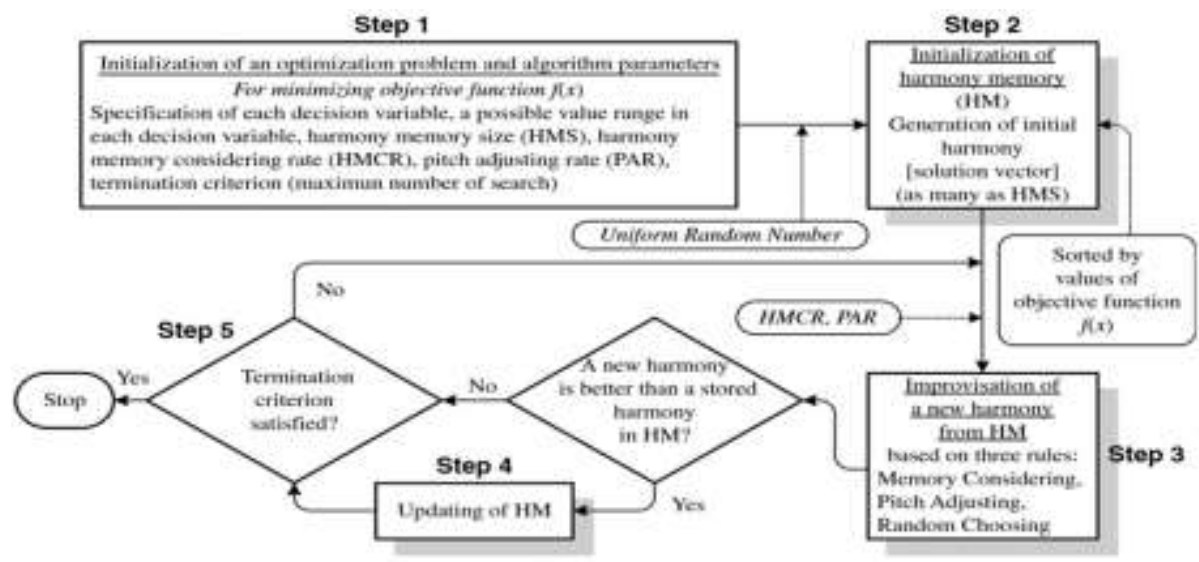

Figure 8. Harmony search algorithm optimization process

\subsection{Objective function [17]:}

The objective function aims to minimize the error of voltage and active power. This means better system performance, faster response and longer connection time between wind turbine and grid. Many performance criterias are used to reach optimum solution. For example; integrated absolute error (IAE), integrated square error (ISE), Integrated time-weighted-squared-error (ITSE) and-integral time-weightedabsolute error (ITAE). All of these methods are represented in the next [5-8] respectively.

$$
\begin{aligned}
& \mathrm{IAE}=\int_{0}^{t}\left|\Delta V_{e}\right| d t \\
& \mathrm{ISE}=\int_{0}^{t}\left(\Delta V_{e}\right)^{2} d t \\
& \mathrm{ITSE}=\int_{0}^{t} t\left(\Delta V_{e}\right)^{2} d t \\
& \mathrm{ITAE}=\int_{0}^{t} t\left|\Delta V_{e}\right| d t
\end{aligned}
$$

The used objective function is ISE in all calculations. It's characterized by small maximum overshoot (Mp) and long settling time (Ts) as it weights all errors equally, time independent. Although ITSE method can overcome his demerit, but it has complex analytic formula and longer time consumption. 


\subsection{Simulation results and analysis:-}

To find out the effect of blade angle control on power system stability of grid connected wind turbine. The System shown in Figure 6 will be studied at three different cases. Firstly, it will be studied at its normal operation condition, with no fault occurrence, in case of variable wind speed. Secondly, it will be studied at fault condition, line to ground fault, in the middle of the transmission line at constant wind speed. Thirdly, it will be studied at its faulted condition, same as previous case study, but with variable wind speed. A comparison will be done in all previous case studies with the optimized gain $(\mathrm{Kp})$ of the pitch angle controller. Pitch angle controller based on HAS will be used. The Line to ground (L-G) fault in the middle of transmission line is supposed to be between (20 to 25 ) seconds.

\subsection{First case, normal operation and variable wind speed (before $\&$ after) optimization:-}

\subsubsection{Wind speed curve:-}

Figure 9 shows wind speed curve illustrating its variability nature. Due to wind speed variance especially at (sec 27 till sec 44.11) a reduced energy is captured by blades. This may lead to under speed condition. This wind speed will be applied in model of Figure 6 in the next sections studying its effect on voltage and power curves performances with and without optimized blade angle controller gain "Kp" as shown in Table 1.

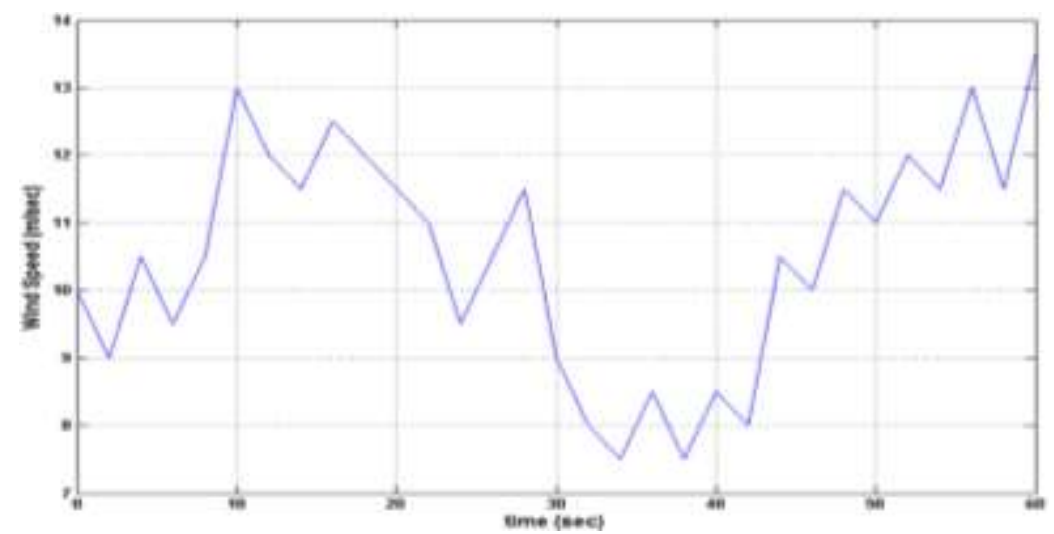

Figure 9. Wind speed curve versus time

\subsubsection{Voltage at bus B575 (P.U)}

Figure 10 shows voltage curves at bus (B575) before and after optimization at their rated value (1 P.U). There are no changes noticed in voltage curve as there is no fault occurred. The wind speed varience will affect delivered power to the generator without affecting voltage of the bus at common coupling point (BCC).

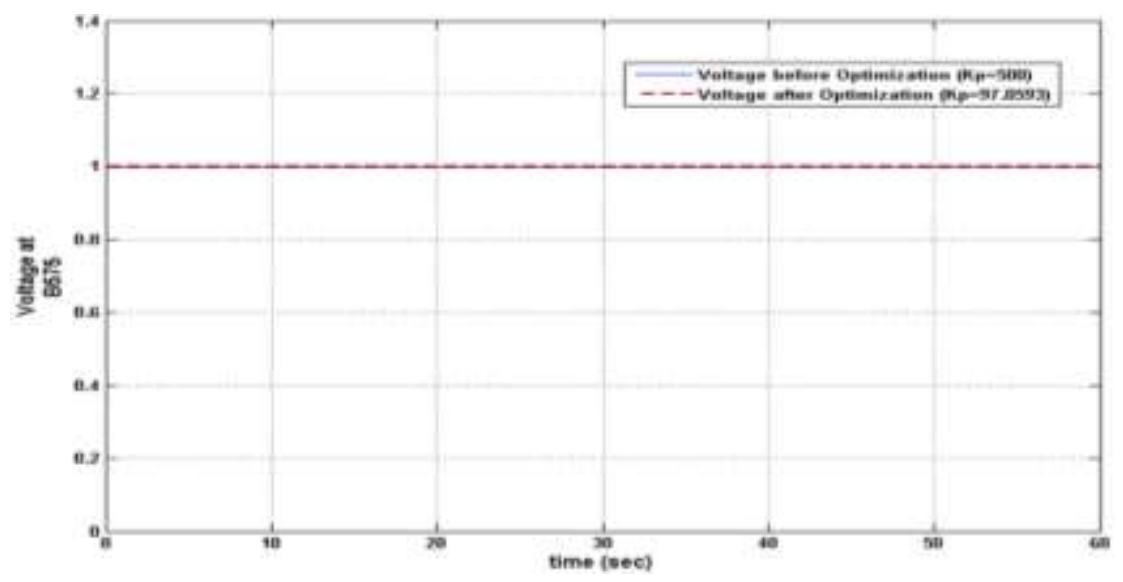

Figure 10. Voltage (before \& after) optimization at wind farm Bus (B575) 


\subsubsection{2 active power (P.U)}

Figure 11 shows active power curves (before \& after) optimization. Figure 11 shows preference of power curve after optimization over its values without optimization. It shows that the optimized gain of pitch angle has increased energy captured enhancing energy efficiency. Also, it prevented power curve from falling at time between ( $\mathrm{sec} 16.75$ to sec 20.22), ( $\mathrm{sec} 21.5$ to sec 23 ) and (sec 44.5 to sec 45.2 ) at which the power, before optimization, has fallen to values of (0.2 P.U), (0.8 P.U) and (0.73 P.U) respectively due to reduction in wind speed. These optimized values of blades angles helped the wind turbine to achieve stable and reliable operation. Also, it enhaned its ability to stay connected to the grid.

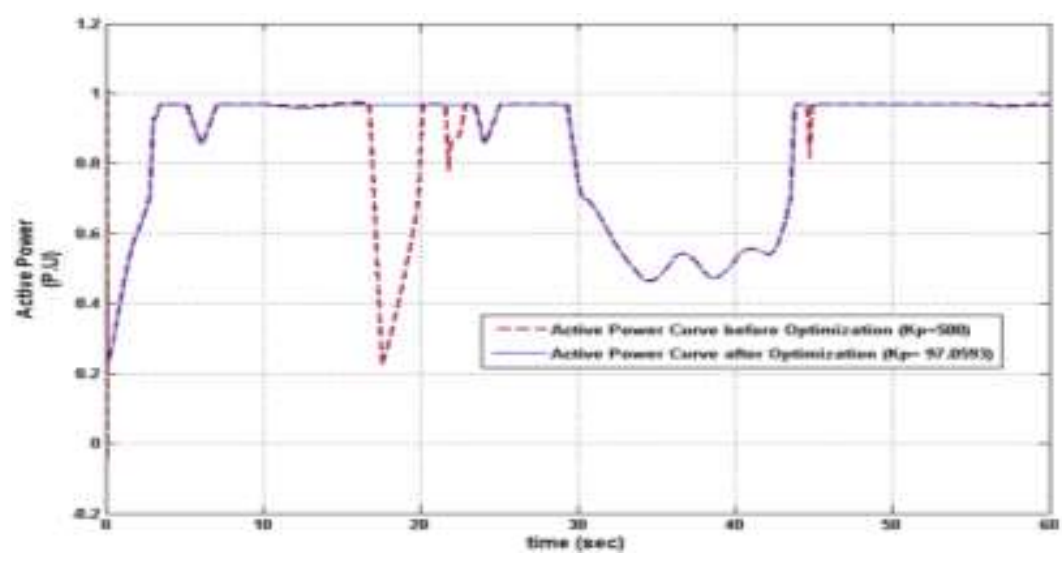

Figure 11. Active power curves (before \& after) optimization

\subsubsection{Reactive power (P.U)}

Figure 12 shows reactive power curves (before $\&$ after) optimization. It shows a slightly difference between two curves. At time between ( $\mathrm{sec} 17$ to sec 20.3) reactive power, before optimization, has been injected to the system to compensate reduction in delivered power. The reactive power curve, after optimization, shows more stable operation as optimized pitch angle controller. At time between (sec 29.5 to sec 44) both curves shows rising up to inject the system with reactive power as the wind speed sharply reduced at this time.

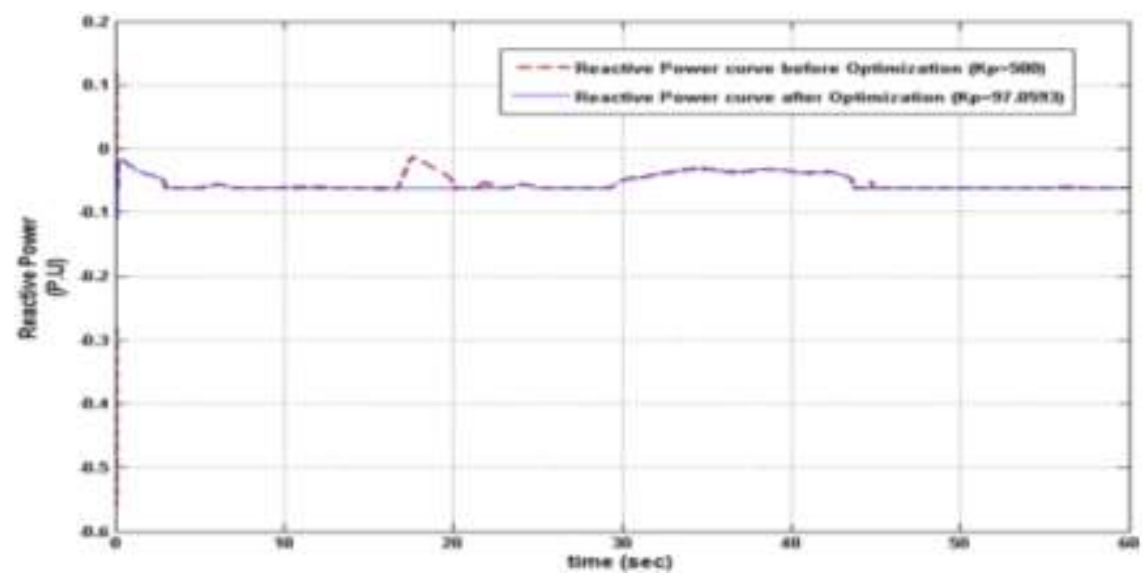

Figure 12. Reactive power curves (before \& after) optimization

\subsubsection{Pitch angle (deg)}

Figure 13 and Table 1 show pitch angle curves (before \& after) optimization conditions. Figure 13 illustrates slightly changes between two curves especially at time between (sec 17 to sec 23.3). It shows a different behavior of optimized blades angles in order to keep energy captured close to its rated value $(0.9$ P.U) despite of reduction in wind speed condition. 


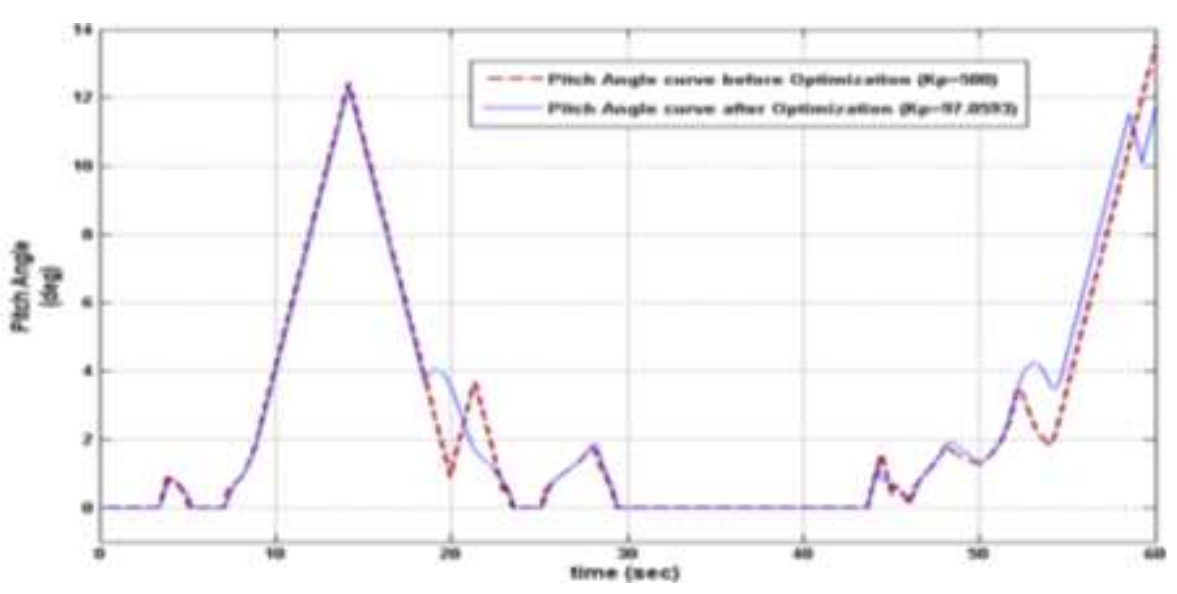

Figure 13. Pitch angle curves (before \& after) optimization

Table 1. Pitch Angle Controller Gain "Kp" values with and without Optimization

\begin{tabular}{cc}
\hline Kp without Optimization & Kp with Optimization \\
\hline $\mathrm{Kp}=500$ & $\mathrm{Kp}=97.0593$ \\
\hline
\end{tabular}

Second case, fault condition, line to ground fault at the middle of transmission line, and constant wind speed (before \& after) optimization. The fault occurrence time will be from (sec 20 to sec 25). The wind speed will be kept constant at $(15 \mathrm{~m} / \mathrm{sec})$.

\subsubsection{Wind speed curve}

Figure 14 shows wind speed curve which is set to constant value of $(15 \mathrm{~m} / \mathrm{sec})$. This case shall help for better understanding for the effect of optimized pitch angle controller gain (Kp) on both active and reactive power curves performance at fault condition. This wind speed will be applied in model of Figure 6. In the next sections studying its effect on voltage and power curves performances with and without optimization of blade angle controller gain "Kp" as shown in Table 2.

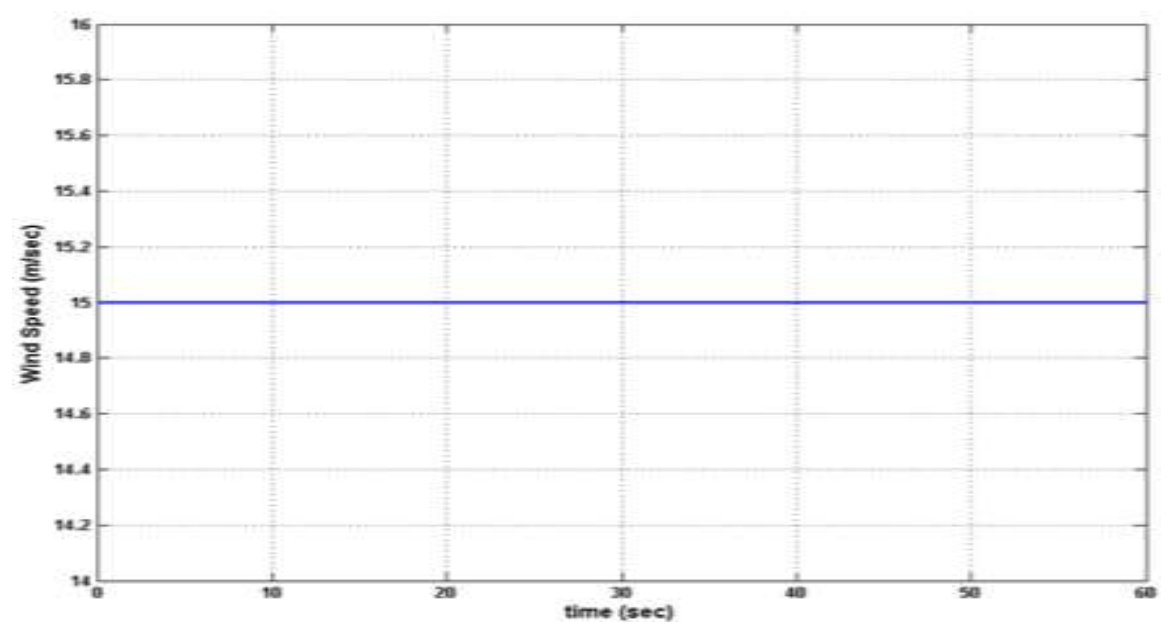

Figure 14. Wind speed curve versus time

\subsubsection{Voltage at Bus B575 (P.U)}

Figure 15 shows voltage curves at bus (B575) before and after optimization. Figure illustrates aslightly improvement in voltage curve especially during fault. The voltage curve in case of optimized pitch angle controller has fallen to (0.9 P.U) while it has fallen to (0.8 P.U) in case of without optimization. 
However, voltage curve after optimization is subjected to higher degree of oscillation than other curve. These oscillation can be decreased by injecting an improved controller technique into the system.

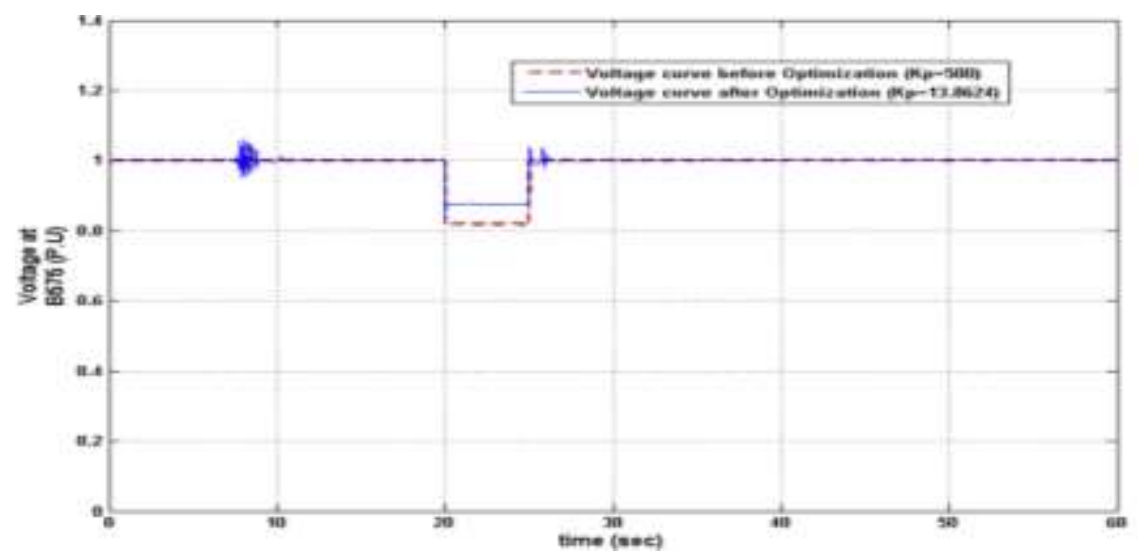

Figure 15. Voltage (before \& after) optimization at wind farm Bus (B575)

\subsubsection{Active power (P.U)}

Figure 16 clarifies the effect of optimized pitch angle on keeping the wind turbine connected through accidental disturbance such as line to ground fault. Figure 16 shows both active power curves (before $\&$ after) optimization rising almost to their rated value of (1 P.U) after overcoming the inertia forces and mechanical losses. Then, power curve before optimization has collapsed at time $(8.3 \mathrm{sec})$ to zero value. This happened because of the wind turbine protection threshold which cut-off the turbine as it reached over current condition. On the other hand, active power curve after optimization oscillates above the rated value (between 1.5/0.5 P.U) values at time between ( $\mathrm{sec} 8$ to sec 14). Then, the curve settled down till the time of fault occurrence. It's shown that the power curve has raised at fault time ( $\sec 20$ to sec 25) helping wind turbine to stay connected and ride through fault. The power curve of optimized pitch angle is subjected to higher degree of oscillation which it can be reduced by injecting an improved controller technique into the system.

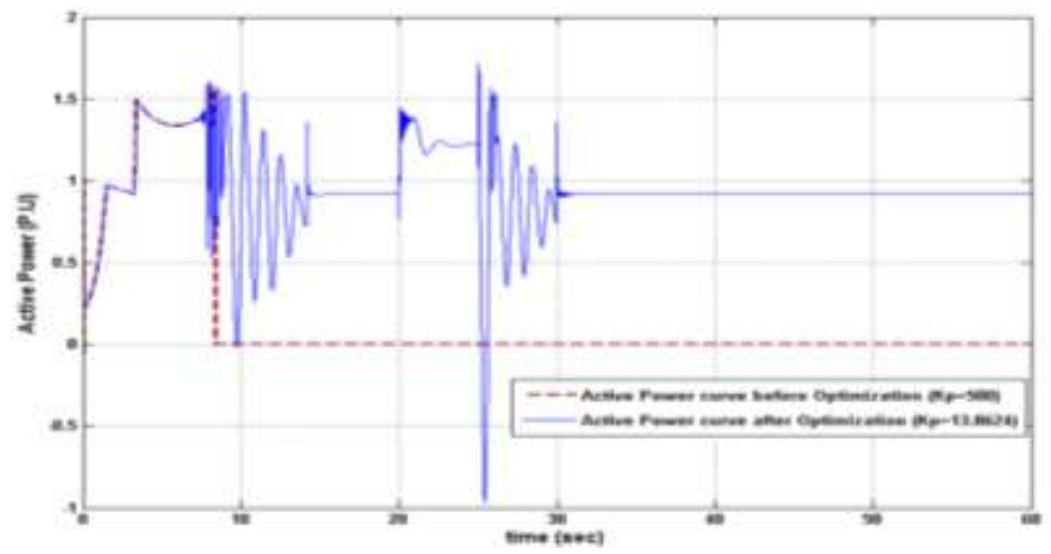

Figure 16. Active power curves (before \& after) optimization

\subsubsection{Reactive Power (P.U)}

Figure 17 shows reactive power curves (before \& after) optimization. It shows reactive power curve before optimization at zero value till the turbine is tripped out from grid at time $(8.3 \mathrm{sec})$ due to over speed condition. Also, the figure shows the after optimization curve of reactive power increased at fault time between ( $\sec 20$ to $\sec 25)$ to value of $(0.9$ P.U). Reactive power is injected at fault time to compensate current absorbed at faulted Point. Figure 17 declared the effect of optimized gain (Kp) of pitch angle in 
keeping the wind turbine connected to the grid and riding through fault occurred. However, it shows high oscillation in reactive power curve, after optimization case, which is can be diminished by injecting an improved controller technique into the system.

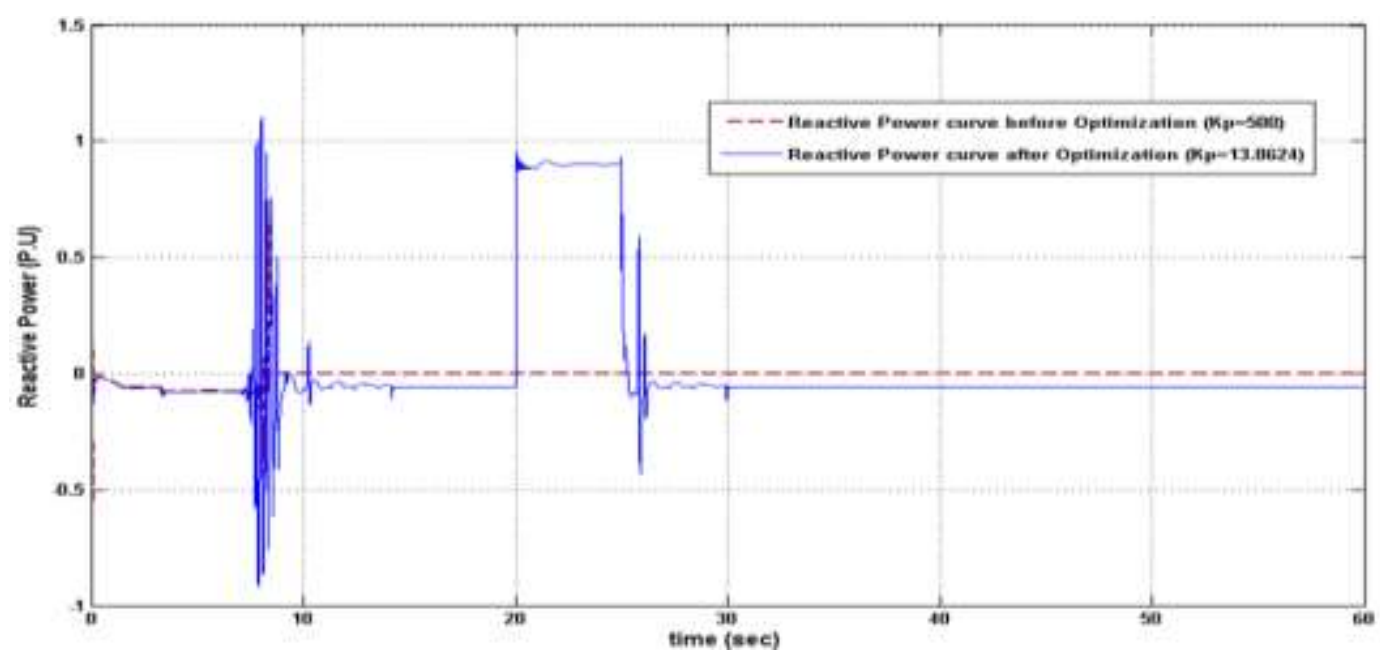

Figure 17. Reactive power curves (before $\&$ after) optimization

\subsubsection{Pitch angle (deg)}

Figure 18 and Table 2 show pitch angle curves (before \& after) optimization. More controllable variation in blades angles has been indicated in pitch angle curve after optimization $(\mathrm{Kp}=13.8624)$. This shall enhance its stability. Also, it shows that lower values of pitch angles allowed more energy captured by wind turbine improving its performance. Optimized pitch angle gain $(\mathrm{Kp})$ prohibited the power curve from collapsing to zero at the fault time helping the wind turbine to stay ON for longer time. This will help wind farm operator to ride through system faults and to fulfill the grid code requirements.

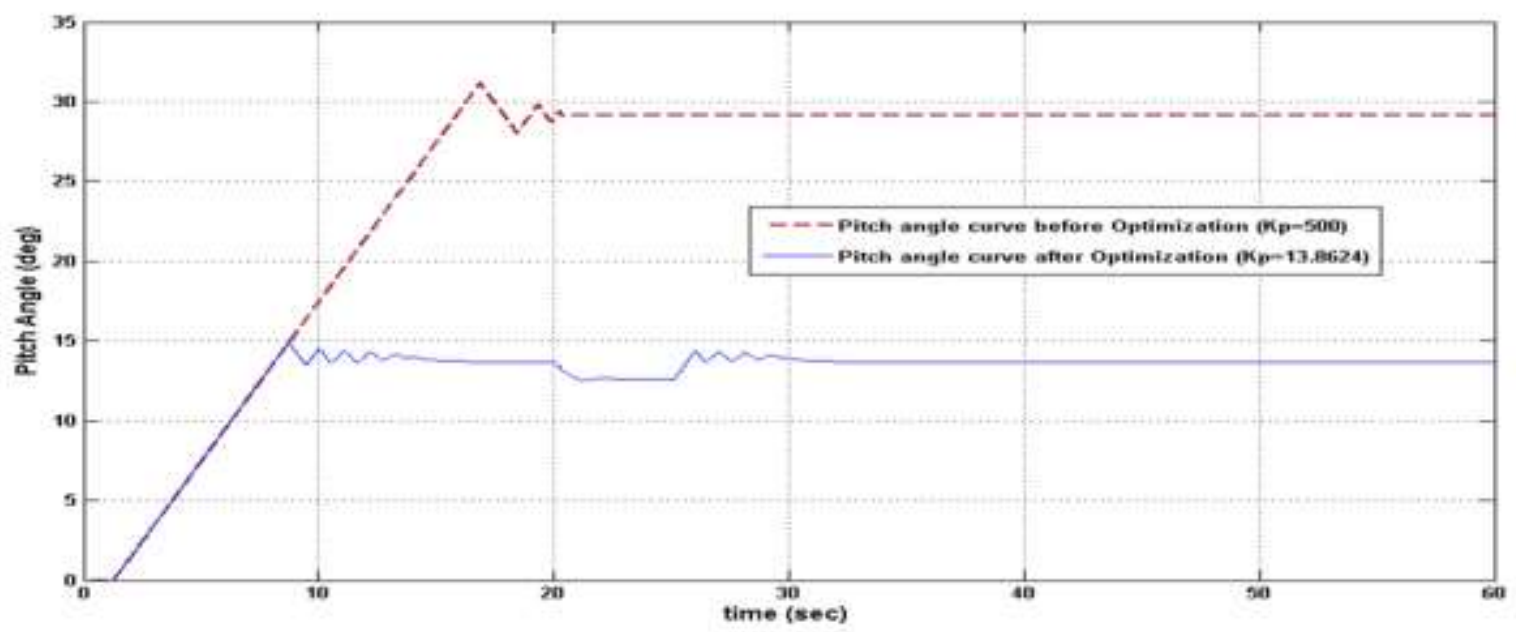

Figure 18. Pitch angle curves (before \& after) optimization

Table 2. Pitch Angle Controller Gain "Kp" Values with and without Optimization

\begin{tabular}{cc}
\hline Kp without Optimization & $\mathrm{Kp}$ with Optimization \\
\hline $\mathrm{Kp}=500$ & $\mathrm{Kp}=13.8624$
\end{tabular}


Third case, fault condition, line to ground fault at the middle of transmission line, and variable wind speed (before $\&$ after) optimization. The fault occurrence time will be from ( $\sec 20$ to sec 25 ).

\subsubsection{Wind speed curve}

Figure 19 shows wind speed curve illustrating its variability nature. Due to wind speed variance especially at ( $\sec 27)$ which is concurrent with pitch blades angle come back to last position due to its inertia. This leads to (under speed) condition which will lead to cut off the turbine by the wind turbine protection threshold. This wind speed will be applied in model of Figure 6 in the next sections studying its effect on voltage and power curves performances with and without optimization of blade angle controller gain "Kp" as shown in Table 3.

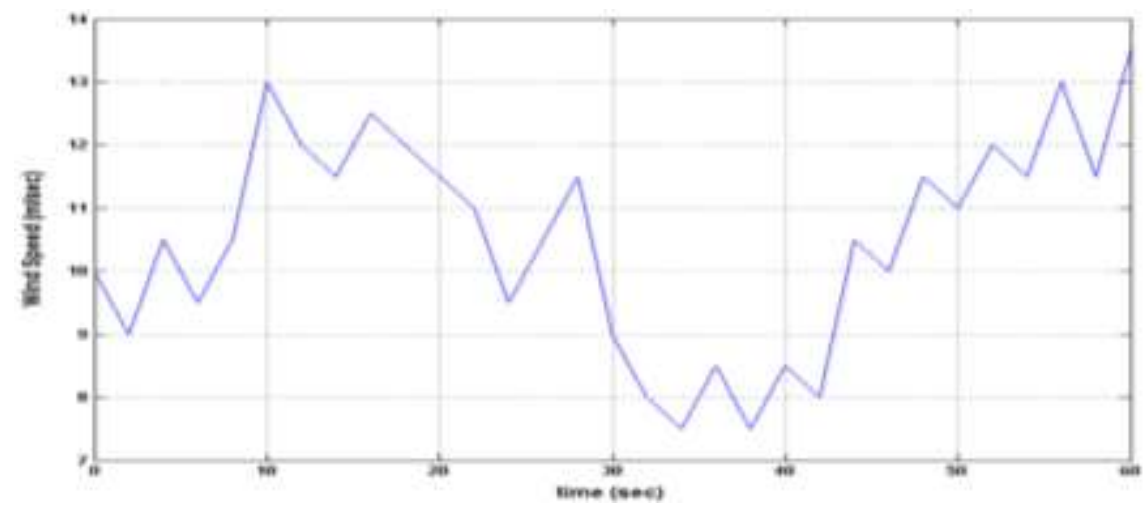

Figure 19. Wind speed curve versus time

\subsubsection{Voltage at Bus B575 (P.U)}

Figure 20 shows visional comparison between voltage performance before and after pitch angle controller gain $(\mathrm{Kp})$ optimization. It shows both curves values at its rated values (1 P.U) till the fault instant $(20 \mathrm{sec})$ when they reduced to nearly $(0.87$ P.U and 0.88 P.U) of their values in case of without and with optimization respectively. This $(15 \%)$ voltage drop is because of passing the fault current at the faulted point. Voltage drop is slightly improved after optimization as the active power transmitted is prevented from collapsing to zero. Curve oscillation is clearly noticed in case of after optimization. However, the curve oscillation can be reduced by injecting an improved controller technique into the system.

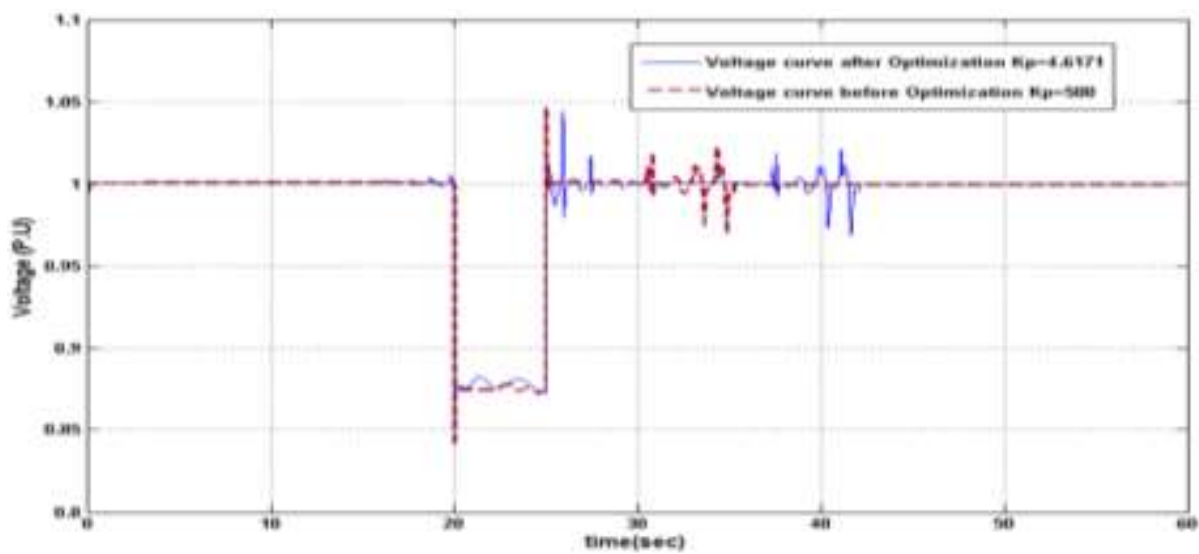

Figure 20. Voltage (before \& after) optimization at wind farm Bus (B575)

\subsubsection{Active Power (P.U)}

Figure 21 shows visional comparison between active power performance before and after pitch angle controller gain $(\mathrm{Kp})$ optimization. After optimization; active power delivered is prohibited from falling 
to zero value at fault time thanks to optimized pitch angle controller. Then the power, after optimization, is oscillating at fault clearance ( $\sec 25)$. At time ( $\mathrm{sec} 30)$ it settled at its rated value (1 P.U). Figure shows the active power before optimization is tripped off at $(37.13 \mathrm{sec})$ while it lasts to longer time of $(42.09 \mathrm{sec})$ in case of after optimization. Therefore, the optimized gain $(\mathrm{Kp})$ has helped the wind turbine to be connected for longer time when the wind speed has reduced to low value close to the (under speed limit) threshold. The power curve in case of after optimization suffers from high oscillation which can be reduced by injecting an improved controller technique into the system.

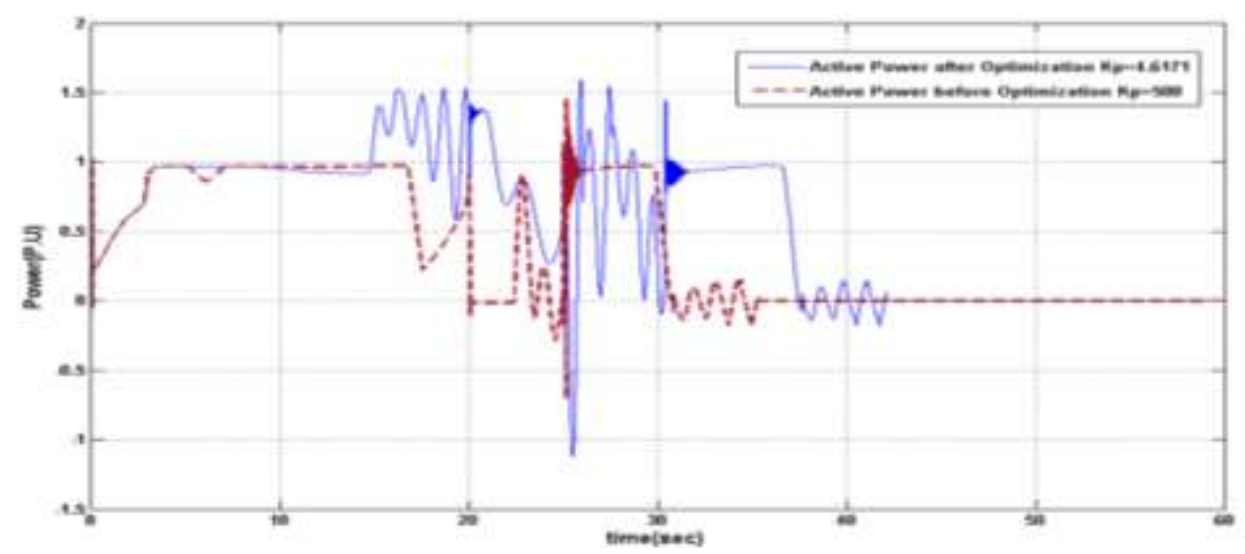

Figure 21. Active power curves (before \& after) optimization

\subsubsection{Reactive power (P.U)}

Figure 22 shows reactive power curves (before \& after) optimization. It shows that both curves are at their zero value till the line to ground fault occurred at time $(20 \mathrm{sec})$. At that time reactive power is injected through the system to retrieve absorbed fault current at the faulted point till the fault clearance time $(25 \mathrm{sec})$. Figure 22 illustrates slightly improvement of curve and longer time of connection, but it shows a high degree of oscillation. These oscillations can be reduced by injecting an improved controller technique into the system.

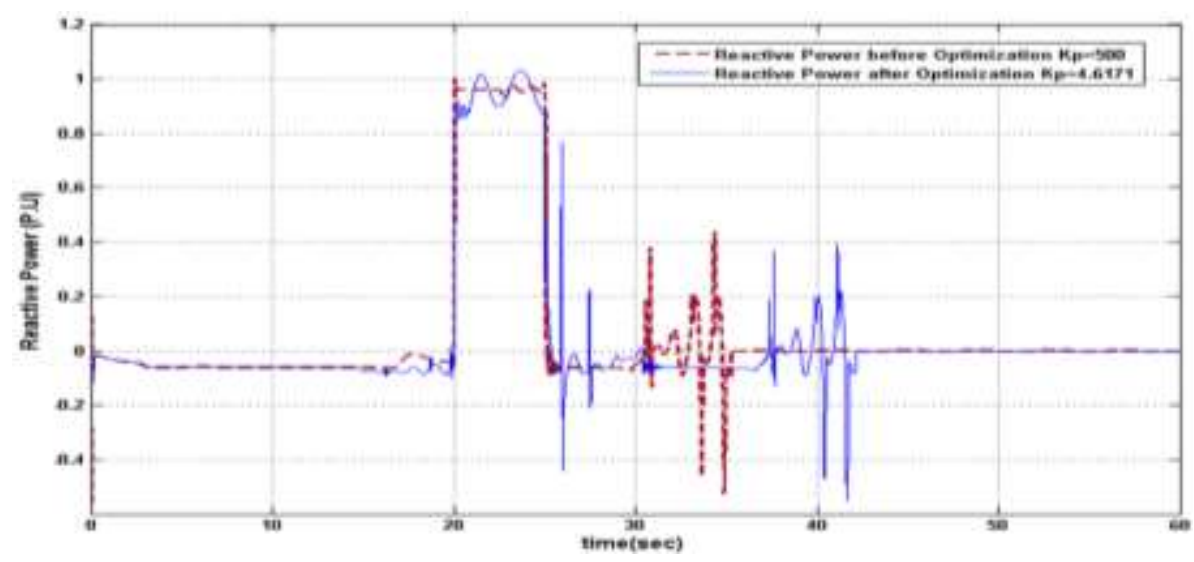

Figure 22. Active power curves (before \& after) optimization

\subsubsection{Pitch angle (deg)}

Figure 23 and Table 3 show visional comparison between Pitch Angle Performance before and after optimization. The curve became lower, more stable as the variance of wind speed became more controllable. Thus helped the wind turbine to stay connected for longer time, from ( $37.13 \mathrm{sec}$ to $42.09 \mathrm{sec})$, before the wind protection threshold trip it as it reached the Under Speed limit due to wind speed variance. 


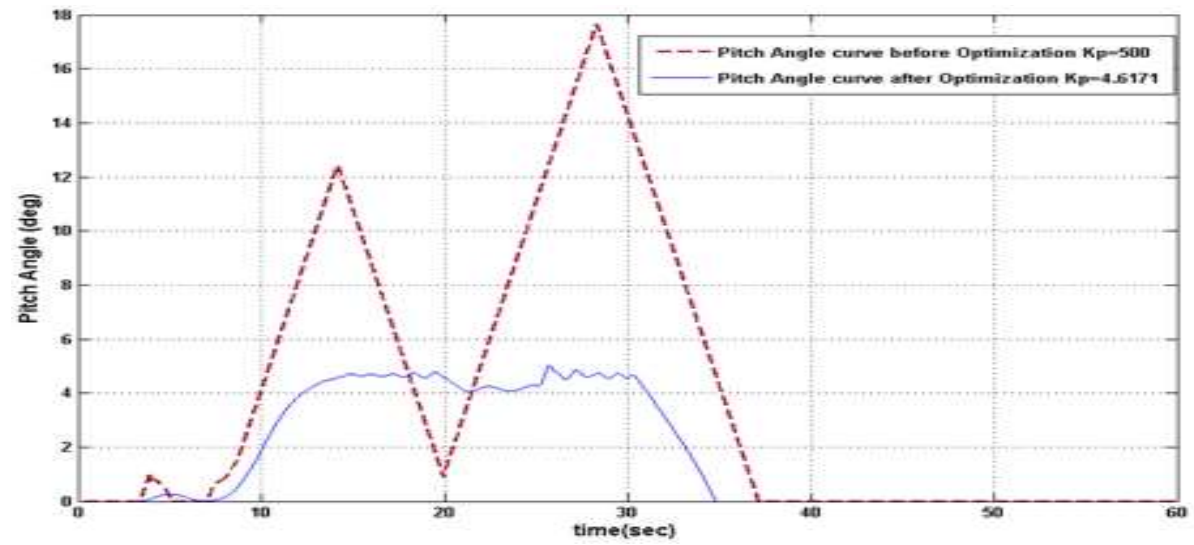

Figure 23. Pitch angle curves (before $\&$ after) optimization

Table 3. Pitch Angle Controller Gain "Kp" Values with and without Optimization

\begin{tabular}{cc}
\hline Kp without Optimization & Kp with Optimization \\
\hline $\mathrm{Kp}=500$ & $\mathrm{Kp}=4.6171$ \\
\hline
\end{tabular}

\section{CONCLUSION}

In this paper the Preference of DFIG over other machines have been discussed. Also an attempt is made to use the MATLAB/SIMULINK to investigate the effects of wind speed variability nature on Wind Turbine performance. Hence, it discussed how to control wind speed variability with the help of optimized pitch angle controller based on harmony search algorithm. As observed, simulation results indicate the influence of blades angels' adjustment on the active power curve. It prevented it from falling to zero value helping the wind farm operator to ride through faults without being disconnected from the grid. Also it observed that pitch angle curve with optimized gain has become more smooth than its previous value without optimization .This would help the system to stay grid connected for longer period and ride through fault occurred in the middle of the transmission line even though the sharp variance of wind speed curve. As it reached the Under Speed limit determined by the wind turbine protection threshold, system has been tripped out from grid. The results of second and third cases illustrate that the system after optimization is subjected to high curve oscillation. These oscillations can be treated using any reactive power compensation technique or by injecting an improved controller technique into the system.

\section{REFERENCES}

[1] Y. Amirat, M. E. H. Benbouzid, B. Bensaker, R. Wamkeue, " Generators for Wind Energy Conversion Systems: State of the Art and Coming Attractions", J. Electrical Systems, Vol.3, No.1, 2007.

[2] Olimpo Anaya-Lara, Nick Jenkins, Janaka Ekanayake, Phill Cartwright, Mike Hughes, "Wind energy generation: modelling and control", John Wiley \& Sons, Ltd, ISBN: 978-0-470-71433-1 (HB), 2009

[3] Subramanian Chandrasekaran, Domenico Casadei, "Grid Connected Doubly Fed Induction Generator Based Wind Turbine under LVRT', PHD study at University of Bologna, Italy, March 2014

[4] Sathyajith Mathew, Geeta Susan Philip, "Advances in Wind Energy Conversion Technology", Springer-Verlag Berlin Heidelberg, ISBN 978-3-540-88257-2, 2011

[5] L. Yang, G.Y. Yang, Z. Xu, Z.Y. Dong, K.P. Wong, X. Ma, “Optimall Controller Design of a doubly-fed Induction Generator Wind Turbine System for small signal stability enhancement”, IET Gener. Transm. Distrib, Vol. 4, No. 5, pp. 579-597, 2010.

[6] P.W. Carlin, A.S. Laxson, E.B. Muljadi,"'The History and State of the Art of Variable-Speed Wind Turbine Technology", National Renewable Energy Laboratory "NREL", Midwest Research Institute, Battelle, Bechtel, TP500-28607, Feb 2001

[7] S. Muller, M. Deicke, R.W. De Doncker," Doubly fed induction generator systems for wind turbines", IEEE Industry Applications Magazine, Vol. 8, No. 3, May/Jun 2002.

[8] Brendan Fox, Damian Flynn, Leslie Bryans, Nick Jenkins, David Milborrow, Mark O’Malley, Richard Watson and Olimpo Anaya-Lara, "Wind Power Integration Connection and system operational aspects", The Institution of Engineering and Technology "IET", London, United Kingdom, ISBN 978-0-86341-449-7, 2007

[9] Shuai Xiao, Hua Geng, Honglin Zhou, Geng Yang, "Analysis Of The Control limit for Rotor Side Converter of doubly fed induction generator-based wind energy conversion system under various voltage dips", IET Gener. Transm. Distrib, Vol. 7, No. 1, pp. 71-81, 2013. 
[10] A. Basak, K. Mukherjee and P. Syam, "Speed control of a grid connected doubly-fed induction generator system for maximum power point tracking with improved input power factor employing matrix converter as a slip power exchanger," 2016 IEEE First International Conference on Control, Measurement and Instrumentation (CMI), Kolkata, pp. 42-47, 2016.

[11] T. L. Van, T. H. Nguyen and D. Lee, "Advanced Pitch Angle Control Based on Fuzzy Logic for Variable-Speed Wind Turbine Systems," in IEEE Transactions on Energy Conversion, Vol. 30, No. 2, pp. 578-587, 2015.

[12] Marwa Ayadi, Fatma Ben Salem, Nabil Derbel, "Sliding mode approach for blade pitch angle control wind turbine using PMSG under DTC", 16th International Conference on Sciences and Techniques of Automatic Control and Computer Engineering (STA), IEEE, December 2015.

[13] David Cortés Vega, Juan Anzurez Marin, Roberto Tapia Sánchez, "Pitch angle controllers design for a horizontal axis wind turbine", International Autumn Meeting on Power, Electronics and Computing (ROPEC), IEEE, 2015

[14] Matlab Simulink model for DFIG, "power_dfig".

[15] Zong Woo Geem, "Music-Inspired Harmony Search Algorithm- Theory andApplications", Springer-Verlag Berlin Heidelberg, ISBN 978-3-642-00184-0, 2009.

[16] Zong Woo Geem, Joong Hoon Kim, G.V. Loganathan, "A new heuristic optimization algorithm: Harmony search Simulation", Simulation Concil Inc "SIMULATION", Vol. 76, No. 2, 2001.

[17] Ahmed M. Mosaad, Mahmoud A. Attia, Almoataz Y. Abdelaziz, "Optimization Techniques to tune the PID and PIDA controllers for AVR Performance Enhancement", i-manager's Journal on Instrumentation \& Control Engineering, Vol. 5, No. 1, November 2016. 